\title{
Electrical and Thermal Properties of Poly(methylmetacrylate) Composites Filled With Electrolytic Copper Powder
}

\author{
Z. Janković, M. M. Pavlović, ${ }^{2, *}$, M. R. Pantović Pavlovic ${ }^{2}$, M. G. Pavlović ${ }^{2}$, N. D. Nikolić ${ }^{2}$, \\ J. S. Stevanovic ${ }^{2}$, S. Pršic ${ }^{3}$ \\ ${ }^{1}$ V\&Z Zaštita, d.o.o., B. Luka, Republic of Srpska, Bosnia and Herzegovina \\ ${ }^{2}$ University of Belgrade, ICTM-CEH, Njegoševa 12, Belgrade, Serbia \\ ${ }^{3}$ University of Belgrade, IMSI, Kneza Višeslava 1, Belgrade, Serbia \\ *E-mail: mpavlovic@tmf.bg.ac.rs
}

Received: 5 September 2017 / Accepted: 26 October 2017 / Online Published: 1 December 2017

The results of experimental studies of the properties of composite materials based on poly(methylmetacrylate) (PMMA) matrices filled with electrolytic copper powder, having very high dendritic structure, are presented in this manuscript. Copper powder volume fractions used as filler in all prepared composites were varied in the range of $0.5-8.8 \%(\mathrm{v} / \mathrm{v})$. The samples were prepared by hot molding injection at $180^{\circ} \mathrm{C}$. Influence of particle size and morphology on the conductivity and percolation threshold and thermal properties of the composites were examined and characterization included: Scanning Electron Microscopy (SEM), Energy-dispersive X-ray spectroscopy (EDS), Thermogravimetric Analysis (TGA), Differential Scanning Calorimetry (DSC), Atomic Forces Microscopy (AFM). Composites have shown improvement of thermal characteristics in relation to pure polymer. Presence of three dimensional conductive pathways was confirmed. The obtained percolation threshold of $2.89 \%(\mathrm{v} / \mathrm{v})$ is about three times lower than the one stated in the literature, which is ascribed to different morphology of filler used in investigation.

Keywords: electrical conductivity, thermal stability, composite materials, lignocellulose, PMMA

\section{INTRODUCTION}

Composite materials possess variety of different properties, hence these marvels of engineering are broadly used in almost all areas of industry and science, especially in automotive, electrical and electronic, aerospace and machine building industries, sport and leisure industry, civil engineering, etc. [1-5]. In recent years, in literature, numerous information on the possibilities of application of polymers containing dispersed conductive fillers, as well as various methods for producing such 
materials can be found [6-12]. Composites with metal fillers have found application as electromagnetic protection of computers and electronic equipment, conductive adhesives for electronic equipment, cold solders, switches, materials for dissipation of static electricity in devices for protection against power surges, counter electrodes for dye-sensitized solar cells [1, 3, 4, 11, 13-17]. They also found numerous technological applications as self-regulating heaters, photothermal optical recorders, chemical sensors and electronic noses, chemical and electrochemical catalysts and adsorbents, supercapacitors, solid electrolytes [18-22]. Electrically conductive polymer composites have several advantages over their constituents, which include lower cost and ease of production, high flexibility, reduced weight, greater ability to absorb mechanical shocks, corrosion resistance and conductivity control [1].

Researches in the field of electroconducting polymer composites filled with metal powders have experienced great development in the last two decades. Adding metal filler polymer matrix allows the preservation of the mechanical properties of polymers while, at the same time, exploiting the electric conductive properties of metal [1]. The electrical conductivity of polymers can be increased by several orders of magnitude by incorporating metallic fillers made of fibers, powders of conducting materials [23-26], or intrinsically conducting polymers [27, 28]. The conductivity of composites with conductive fillers depends on the nature of contacts between the conductive filler particles and filler volume fraction, which is well explained by the percolation theory [29, 30]. The percolation threshold is typically $15-30$ vol\% for spherical particles [31, 32]. However, favourable mechanical properties of a pure polymer are lost at these large volume fraction loadings due to high metal concentration required to achieve electrical conduction. In order to achieve better electrical conductivity of the conductive polymer composites, while saving in material and retaining favourable polymer properties, use of highly developed surfaces fillers is preferred. Theoretical and experimental considerations have shown that use of these fillers lead to the formation of conductive network throughout the entire sample volume at much lower filler volume fractions [33, 34]. However, percolation threshold, electrical conductivity, electrical behavior of composite systems with fillers which have highly developed surface area, and primarily thermal behavior of these materials have not been explored in details. Therefore there is need for more detailed study of real synergetic effects of different fillers dimensionalities suitable for construction of conductive networks in conductive polymer composites. For this reason, the copper powder was galvanostatically produced with distinct dendritic morphology and large surface area.

The need for highly conductive polymer-based materials has been the motivation to develop poly(methylmethacrylate) (PMMA) composites filled with electrodeposited copper powder particles which would retain desirable polymer characteristics, including ease of processing, and obtain high conductivity at low cost. The strategy consisted in manipulating the morphology of the filler so that high conductivity could be achieved at a low percolation threshold. In previous researches [35-38], conductivity of composites based on biodegradable lignocellulose matrix and copper powder has been investigated. The percolation threshold has been lowered to $7.8 \%(\mathrm{v} / \mathrm{v})$ [37, 38], and further investigations were conducted in this research in order to determine the influence of the matrix on electrical conductivity of obtained composites.

This work shows the results of electrical conductivity and thermal stability of PMMA composites filled with galvanostatically produced copper powder particles. 


\section{EXPERIMENTAL}

In the experimental part of the work, poly(methylmethacrylate) (PMMA) was used as matrix. PMMA used was commercial PMMA in form of beads, supplied by Sigma-Aldrich, having average molecular weight of $\mathrm{M}_{\mathrm{w}} \sim 350000$, with a density of $1.20 \mathrm{~g} / \mathrm{cm}^{3}$, and the electrical conductivity of about $10^{-12} \mathrm{~S} / \mathrm{cm}$. Before use, the polymer was dried in a tunnel furnace at $60{ }^{\circ} \mathrm{C}$ in a controlled nitrogen atmosphere.

Copper powder was produced by the galvanostatic regime of electrolysis under following conditions: current density: $j=3600 \mathrm{~A} / \mathrm{m}^{2}$, time of powder growth: $\tau_{\mathrm{r}}=15$ min, electrolyte flow: $Q=1$ change of the cell volume/h, temperature of the electrolyte: $t=(50 \pm 2){ }^{\circ} \mathrm{C}$, concentration of copper: $c\left(\mathrm{Cu}^{+2}\right)=15 \mathrm{~g} / \mathrm{dm}^{3}$ and concentration of sulfuric acid: $c\left(\mathrm{H}_{2} \mathrm{SO}_{4}\right)=140 \mathrm{~g} / \mathrm{dm}^{3}$. In the process of electrolysis, the both cathode and anode were of copper. All electrolytes were prepared from p.a. chemicals obtained from Merck and demineralized water.

Cathode copper from the Mining and Smelting Combine Bor was used as anode material, having the average composition of $99.97 \% \mathrm{Cu}$ and the following impurities $(\mathrm{g} / \mathrm{t}): \mathrm{Ag}=5, \mathrm{Au}=0.1, \mathrm{Bi}$ $=0.5, \mathrm{Ca}=7.0, \mathrm{Fe}=1.3, \mathrm{Ni}=1, \mathrm{~Pb}=0.2, \mathrm{Sb}=0.1, \mathrm{Se}=1, \mathrm{Si}=2, \mathrm{Sn}=2$ and $\mathrm{Zn}=1$. The number of anodes in the cell was 5, with dimensions: $(120 \times 120 \times 10) \mathrm{mm}$. The interelectrode axial distance of the electrodes of the same type was $60 \mathrm{~mm}$.

Drawn copper in a form of comb with 4 rods per cathode was used as cathodic material. There were total of 4 cathodes, each having axial distance between the rods of $30 \mathrm{~mm}$. Length of each rod was $120 \mathrm{~mm}$, and the diameter was $\phi=8 \mathrm{~mm}$. The interelectrode axial distance of the electrodes of different type was $30 \mathrm{~mm}$.

At the end of the precipitation, the powder was removed from the electrode by shaking it.

Because the acid promotes a rapid oxidation of powder during drying process, the produced copper powder was washed with distilled water at the room temperature until the powder was left without traces of acid. After this phase, the copper powder was washed with aqueous solution of a sodium soap SAP G-30 (Henkel Merima) with the aim to protect the powder from succeeding oxidation $[34,35]$. After drying in a tunnel furnace at $110-120{ }^{\circ} \mathrm{C}$ in controlled nitrogen atmosphere, the produced copper powder was sieved through mesh with openings of $45 \mu \mathrm{m}$.

PMMA composites filled with galvanostatically produced copper powder were prepared with the filler volume fraction ranging from $0.5 \%(\mathrm{v} / \mathrm{v})-8.8 \%(\mathrm{v} / \mathrm{v})$. Pure PMMA and copper samples were prepared as reference materials. PMMA was preheated and melted at $t=180{ }^{\circ} \mathrm{C}$ for $30 \mathrm{~min}$. Previously measured amounts of copper powder for given volume fractions of filler were added afterwards and mixed until the mixture was fully homogenized. Samples were produced from this homogenized mixture in the molder, LNS Technologies PIM-SHOOTER ${ }^{\text {TM }}$ Model 150A, having size $5 \times 50 \times 200 \mathrm{~mm}$. After preparation of PMMA composites, samples were cooled at the room temperature for about $30 \mathrm{~min}$. In order to obtain flat surface for conductivity measurements, samples were polished with sandpaper.

Electrical conductivity measurements were carried out by measuring DC U/I characteristics of the samples using Digital Multimeter, Model 464, Simpson Electric Company. Measurements were 
performed in such manner that there was no influence of the geometry of the contacts on conductivity results.

SEM and EDS analysis of PMMA composites and constituents were performed using scanning electron microscope VEGA TS 5130MM microscope (Tescan).

Quantitative microstructural analysis of copper powder was carried out on the Leica Q500 MC automated device. This analysis defines methods for two-dimensional description of the structure, on which basis realistic three-dimensional image of the structure can be determined.

Using the automatic method of characterization of copper powder particles, it is very easy to obtain a large number of parameters from those specific to the measuring field, for example: surface ratio, specific boundary surface, length of the section and number of particles, to those individual parameters for each particle: surface, volume, maximum diameter with the angle of orientation, ferret diameter (projection in $\mathrm{X}$ and $\mathrm{Y}$ direction), focus coordinate and shape factor.

When all the particles have the same shape and size, the circumference of the contour of the particles can be compared with a circle of the same area and dimensionally independent relationship of the actual circumference of the particle and the circumference of the circle can be established. Spherical particles have the value $K=1$; more complicated forms mean that $K>1$.

After the measurements were made, statistical data processing was performed, as well as error estimation. Measurements were performed on 50 randomly chosen individual particles. Measured parameters that characterize metal powder in this paper were:

- $A$ (Area) - The area of the maximum projection of the particle

- $D_{\max }$ - Maximum diameter (length) of the particle

- $D_{\min }$ - Minimum diameter (length) of the particle

- $L_{p}$ (Perimeter) - The total length of the boundary line of the particle. This was calculated from the horizontal and vertical projections, with a tolerance for the number of angles

- $f_{L}$ (Perimeter shape) - Perimeter shape factor. This is calculated from the relationship: $f_{L}=\frac{4 \pi A}{L_{p}^{2}}$, and for circle and ellipse it is 1.

- $f_{R}$ (Roundness) - The shape factor that gives the minimum value for the circle. This is calculated from the ratio of the square to the surface:

$f_{R}=\frac{L_{p}^{2}}{4 \pi A \cdot 1.064}$

The correction factor of 1.064 corrects the circumference for the effects of the angles obtained by digitizing the image.

- $f_{w}$ (Waveness) - This is the ratio of the length of the polygon that describes a particle, formed by tangents to the boundary line of the particle to its circumference [39].

For the illustration of thermal behavior (stability), thermogravimetric analysis was performed on all the samples. Thermogravimeter TA Instruments Q600 thermal analyzer with a heating rate of 10 ${ }^{\circ} \mathrm{C} / \mathrm{min}$ in a dynamic nitrogen atmosphere was used.

TA Instruments Q100 instrument was used for differential scanning calorimetry (DSC analysis) experiments. The analysis was performed from $30^{\circ} \mathrm{C}$ to $200^{\circ} \mathrm{C}$ with a heating rate of $20 \mathrm{oC} / \mathrm{min}$. 
Topographies of obtained PMMA composites were examined by Atomic Forces Microscope, type "Nanoscope III" AFM "Multi Mode Scanning Probe Microscope", produced by "Digital Instruments".

\section{RESULTS AND DISCUSSION}

Figure 1 shows morphology of galvanostatically produced copper powder particles, from which can be noticed very dendritic 3D (three-dimensional) structure of the obtained powder. Aside from morphologic SEM analysis, the obtained $\mathrm{Cu}$ particles were characterized by quantitative microstructural analysis. The mean values of $f_{R}=2.11, f_{L}=0.51$ and $f_{W}=0.90$ obtained for this powder [37] confirm that the produced particles are not compact and round, but have high dendritic character defined by the existence of a stem and well defined primary and secondary branches with angles among them typical for the cubic lattice.

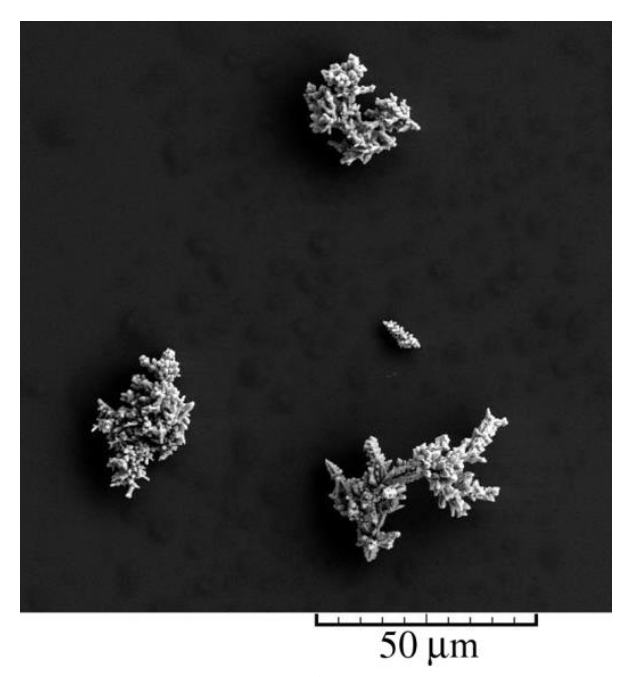

a)

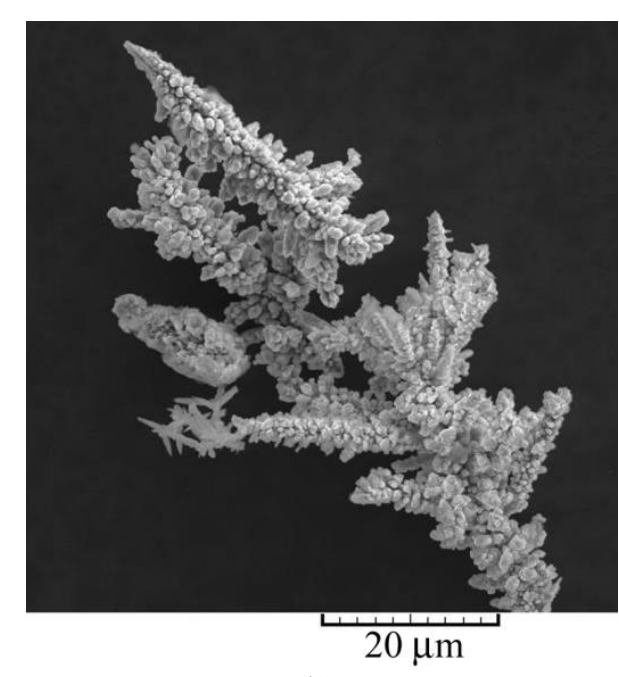

b)

Figure 1. SEM microphotographs of $\mathrm{Cu}$ powder particles obtained by the galvanostatic regime of electrolysis and sieved through mesh $<45 \mu \mathrm{m}$ : a) general view and b) single particle view.

It can be seen from image scales on Figure 1 that typical copper powder particle is $<45 \mu \mathrm{m}$ in size. The high dendritic character of the obtained particles is a good prerequisite for the formation of a larger number of interparticle contacts between the conductive powder particles and lowering of percolation threshold. Also, this very branchy structure of the particles enables formation of multiple contacts with neighboring particles at lower filler volume fractions. As it was already shown by Pavlović et al. [38], the percolation threshold was at the lowest value of $7.2 \% \mathrm{v} / \mathrm{v}$ for lignocellulose (LC) composites filled with the particle size $<45 \mu \mathrm{m}$ and obtained under pressure of $27 \mathrm{MPa}$. For that reason, it was reason why PMMA composites were prepared under the same conditions as those prepared with lignocellulose. 
The electrical conductivity of the PMMA composites as a function of filler content for all prepared samples was measured as stated in Experimental part. The conductivity of PMMA composites, showing typical S-shaped dependency with three distinct regions: dielectric, transition and conductive, as expected, is shown on Figure 2.

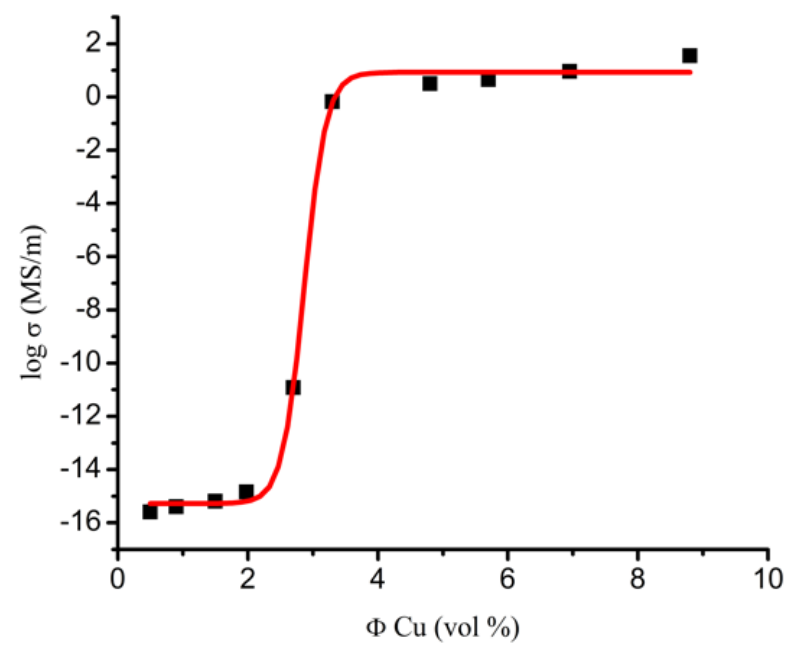

Figure 2. Change in electrical conductivity as a function of filler volume fraction for PMMA composites filled with copper powder.

Percolation threshold value was obtained from the maximum of conductivity derivative as a function of volume fraction of filler. As it can be seen from Figure 2, as well as from calculated value, the percolation threshold was at $2.89 \%(\mathrm{v} / \mathrm{v})$, which is over three times lower than the one obtained by Poblete et al. [1] for the same type of composite. This difference that occurs is most likely due to filler shape, i.e. powder particles, which, in our case, were very dendritic with high-developed free surface area, and hence less filler was needed to form conductive network throughout the composite volume. Namely, Poblete et al. [1] used more regular, rounded shapes of copper powder filler, obtaining higher values of percolation threshold. Experiments have shown that the morphology of the particles plays a crucial role for the percolation threshold appearance. Besides the filler morphology, polymer matrix type, as well as preparation method influences the percolation threshold, which further moves towards lower values.

For investigation of electrical conductivity, as well as for morphology examination of copper powder filled PMMA matrix, cross section of the sample at percolation threshold perpendicular to the surfaces at which the electrical conductivity was measured, was made. This cross section was $5 \times 50$ $\mathrm{mm}$ in size, and it was polished before further investigation. Figure 3 shows SEM image of the cross section of PMMA composite filled with copper powder at percolation threshold. Two different phases can be seen on Figure 3. However, mechanism of the electrical conductivity, as well as interparticle contacts could not be clearly concluded from the Figure 3. For this reason EDS measurements were performed on same cross section of PMMA-Cu composites. These results are shown in Figure 4. 


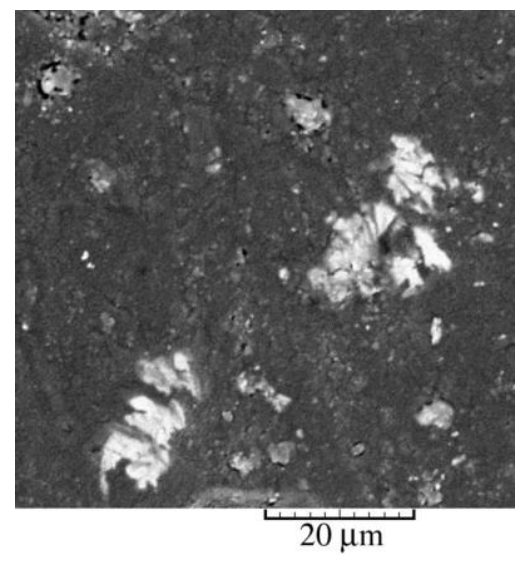

Figure 3. SEM image of cross section of PMMA composite filled with galvanostatically produced copper powder at percolation threshold. Cu powder particle size $<45 \mu \mathrm{m}$.

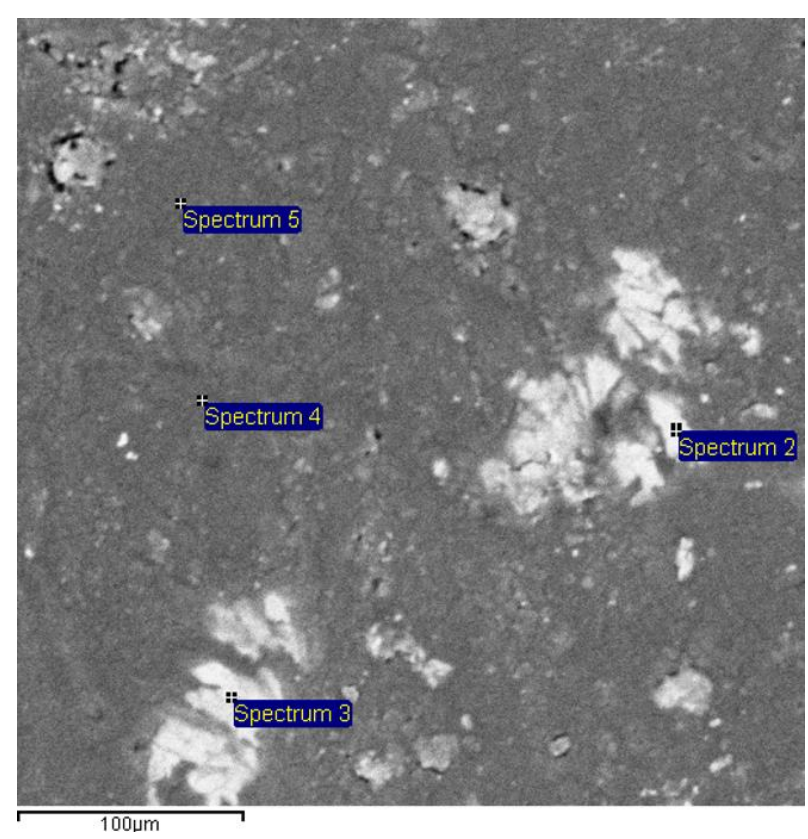

a)
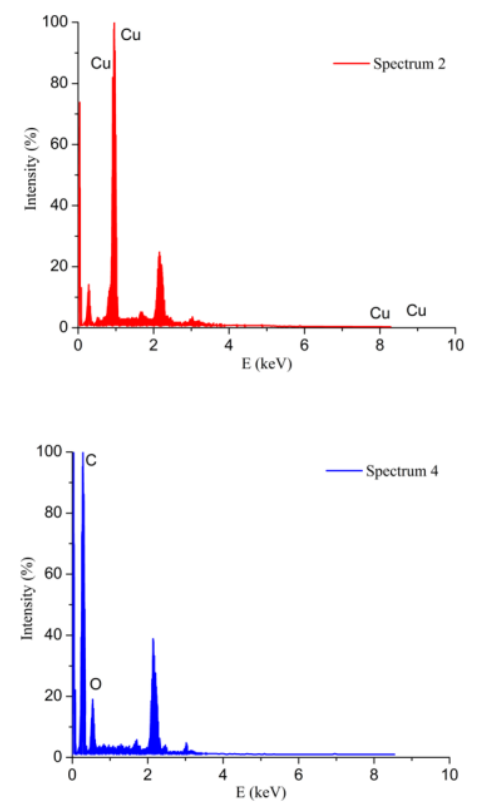

b)

Figure 4. EDS image of cross section of: a) PMMA-Cu composite surface with b) spectrum analysis of different phases.

The light parts in Figure 4a (Spectrum 2) corresponds to $\mathrm{Cu}$, as seen from Figure $4 \mathrm{~b}$. Simultaneously, the dark part (Spectrum 4) corresponds to polymer matrix, i.e. PMMA.

Full surface EDS analysis was also performed on the samples cross section. Results of surface area EDS analysis is shown on Figure 5. Presence of $\mathrm{Cu}$ is presented with white dot, while absence is presented with dark one. 


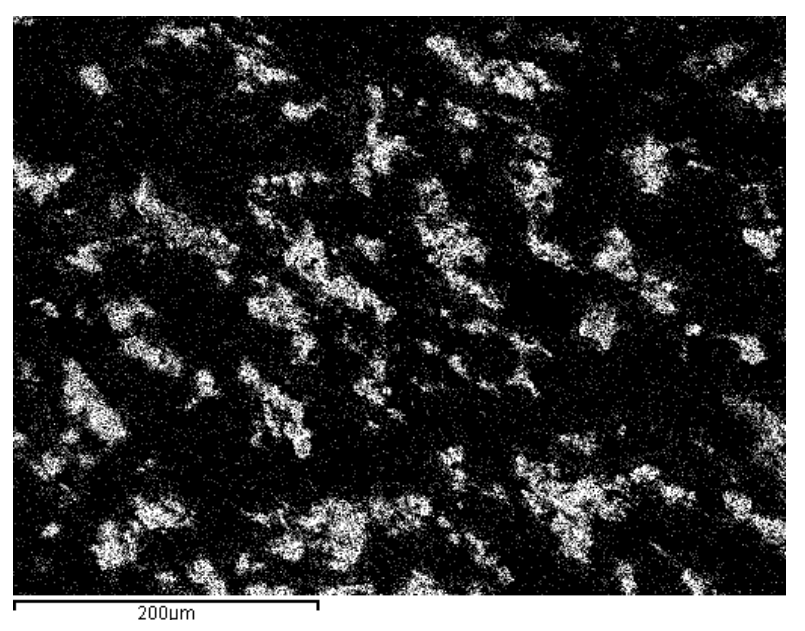

Figure 5. EDS image of PMMA composites prepared at percolation threshold. White dots represent $\mathrm{Cu}$.

The size of $\mathrm{Cu}$ particles that can be identified from Figure 5 (white dots) can be measured by image scale at the bottom of the Figure 5. From the measurements of electric conductivity, and knowing that presented sample is conductive and that it is at percolation threshold, it can be concluded from Figures 4 and 5 that conductive pathways are formed throughout the surface of the composite, since the size of copper phase present in the figures $(>200 \mu \mathrm{m})$ is much larger than size of copper powder particles $(<45 \mu \mathrm{m}$ from Figure 1$)$ used for composite preparation. Clearly, composites conduct electricity through conductive pathways that are formed in 3D in pure random order.

Morphologies of polymer composite obtained after breakage in the 3D form, as well as pure PMMA, were characterized by Atomic Forces Microscopy (AFM) technique and shown in Figure 6. The two different surface morphologies characterized by different RMS roughness can be detected by the careful analysis of the obtained polymer composite. The first one is shown in square in Figure 6b, and this surface morphology is assigned to copper powder. The RMS roughness of this part was 134 $\mathrm{nm}$. The second one is shown in square in Figure $6 \mathrm{c}$ and corresponds to polymer chain or matrix. The RMS roughness of this part was $49 \mathrm{~nm}$.

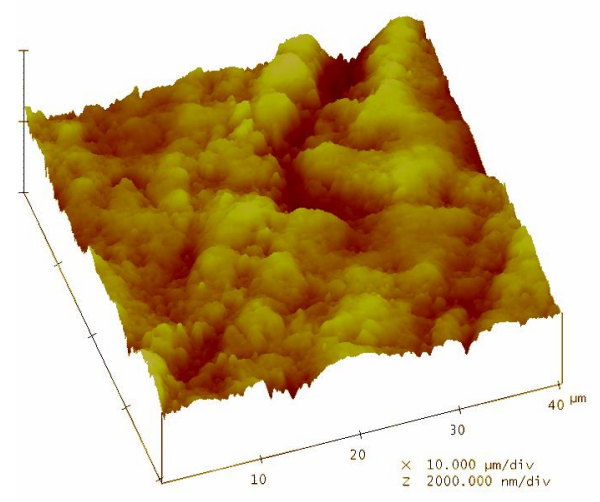

a) 


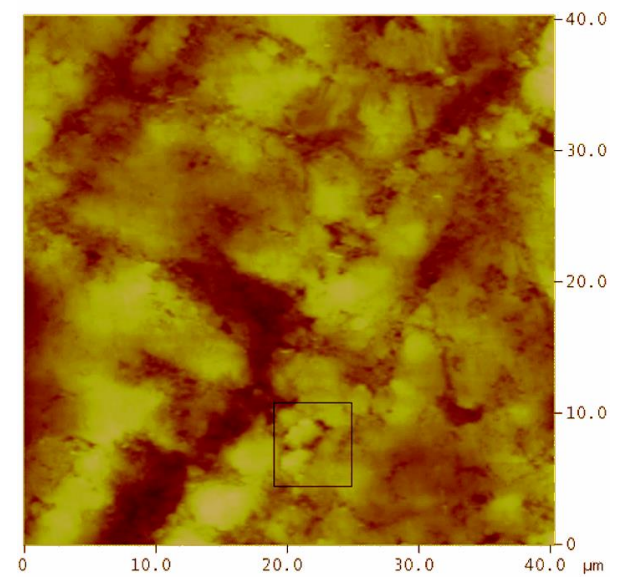

b)

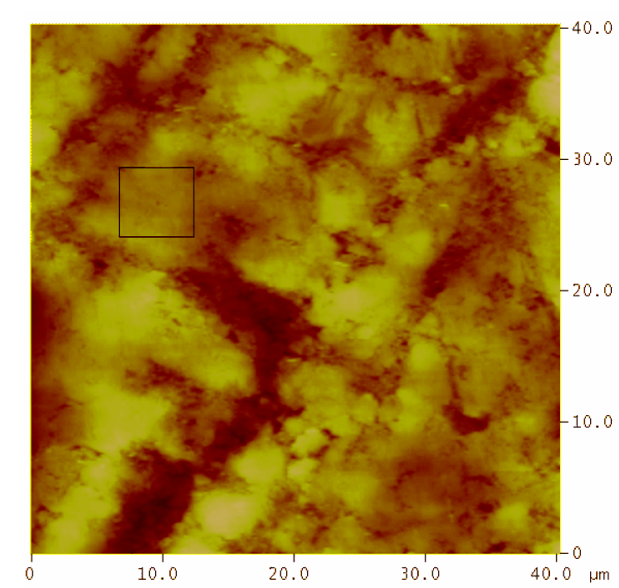

c)

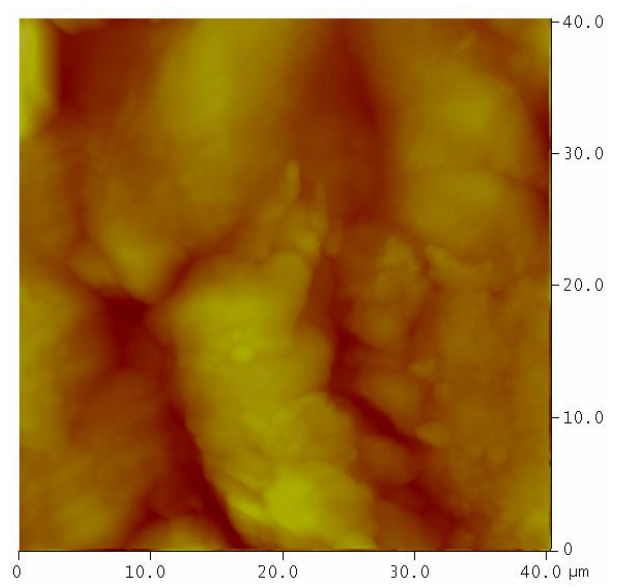

d)

Figure 6. AFM images of polymer composite filled with copper powder at percolation threshold obtained after breakage: a) the 3D view, and the 2D images where the parts in squares correspond to: b) $\mathrm{Cu}$ powder, and c) polymer chain. d) AFM image of pure PMMA polymer.
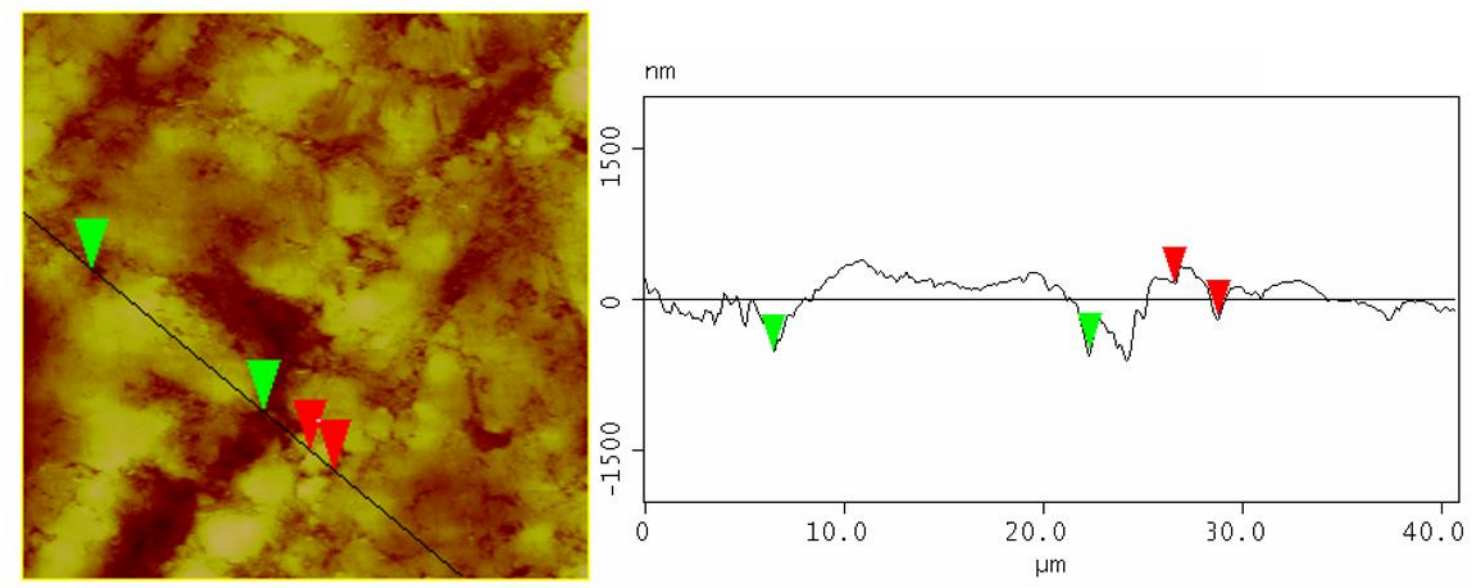

Figure 7. The line sections analysis of the polymer composite. Green markers - polymer chain (PMMA), value of $15.51 \mu \mathrm{m}$; Red markers - Cu powder, value of $2.21 \mu \mathrm{m}$. 
This statement is backed up by AFM RMS measurements of pure PMMA sample, presented in Figure 6d, where RMS roughness of pure PMMA polymer is $50.14 \mathrm{~nm}$. It is clear that the considerably larger roughness of the first part was a consequence of a high developed surface area of dendritic particles (as already observed by the SEM technique).

The line section analysis of the polymer composite (Figure 7) confirms the existence of the two different phases in the polymer. The distance between green markers (larger distance in Figure 7), being $15.91 \mu \mathrm{m}$, defines the polymer chain, while the red markers (smaller distance in Figure 7) correspond to $\mathrm{Cu}$ grains, and the value of observed feature is $2.21 \mu \mathrm{m}$.

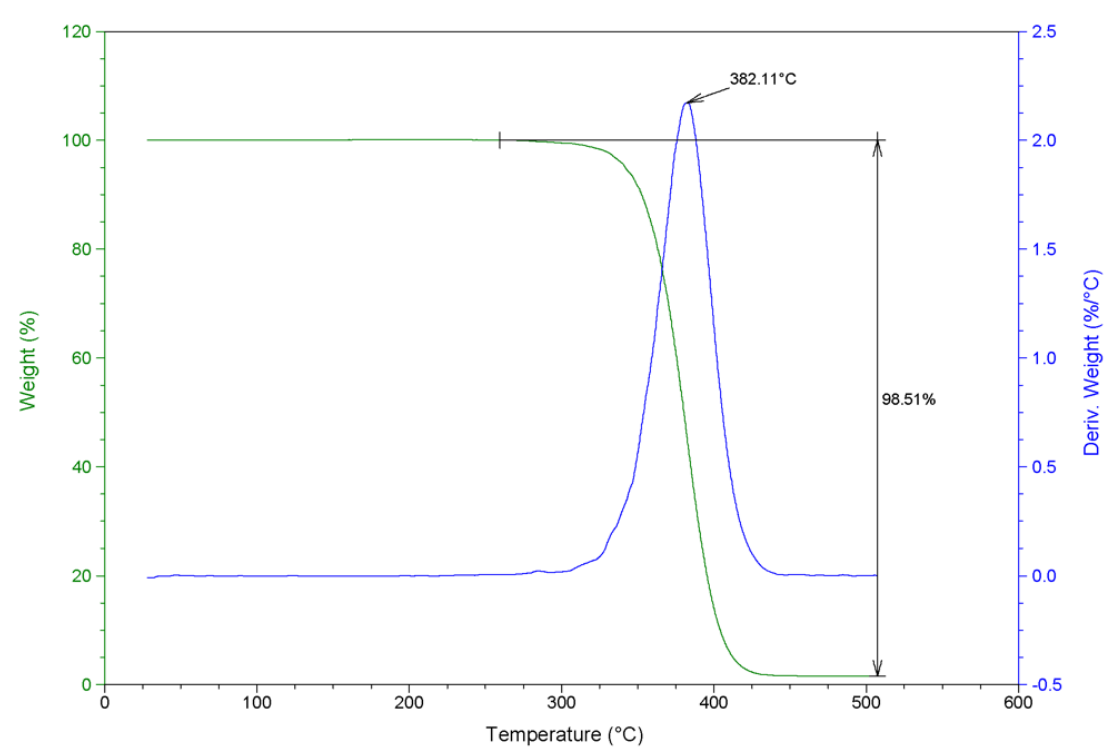

a)

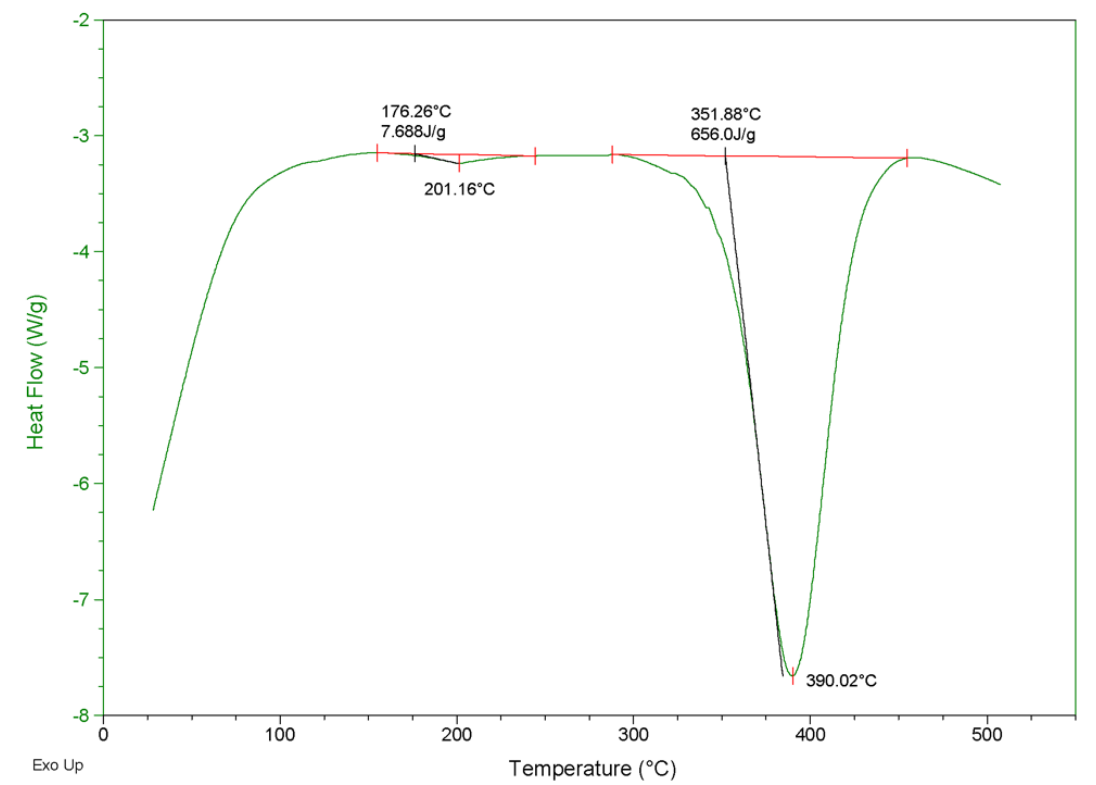

b)

Figure 8. The results of: a) thermogravimetric analysis and b) differential scanning calorimetry measurements of PMMA matrix composites filled with copper powder. 


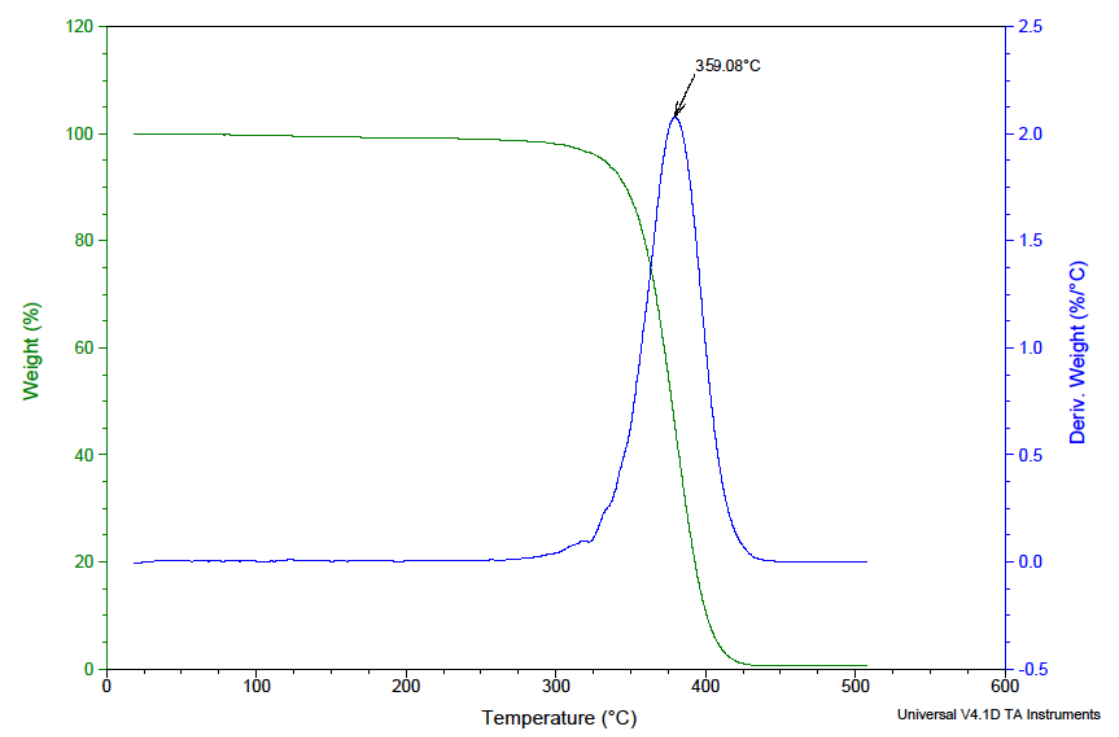

a)

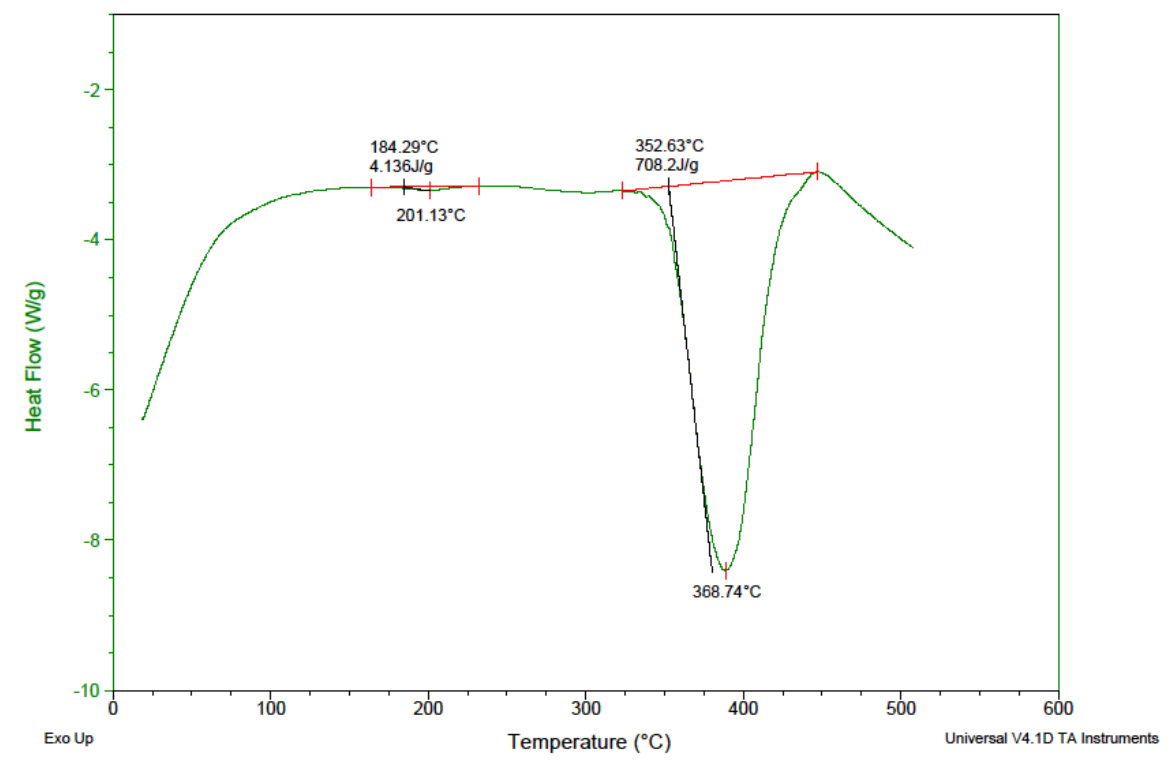

b)

Figure 9. The results of: a) thermogravimetric analysis and b) differential scanning calorimetry measurements of pure PMMA polymer.

TGA curve shown in Figure 8a illustrate the thermal behavior (stability) of PMMA composites filled with electrochemically deposited copper powder at percolation threshold, while DSC curves of the PMMA composite filled with copper powder on the percolation threshold for particle size $\leq 45 \mu \mathrm{m}$ are shown in Figure 8b. Figure 9 illustrates thermal characteristics of pure PMMA polymer. Characteristic temperature of the observed thermal events in Figure 8a corresponds to degradation of the matrix (an event that occurs at $279-382{ }^{\circ} \mathrm{C}$ ) and confirms presence of the main constituents (PMMA). The result showed improvement in the thermal characteristics of the composite in relation to pure polymer due to the presence of copper powder, which is extremely good thermal conductor, so that the amount of heat emitted during the TGA measurements was originally accumulated in the copper powder particles, and only after this accumulation there is a change in matrixes themselves. 
The smaller peak that occurs at $201{ }^{\circ} \mathrm{C}$ on DSC curve corresponds to the temperature of the beginning of melting for both the composite. As well as for TGA, DSC measurements showed improvement in the thermal characteristics of the composite in relation to pure polymer due to the presence of copper powder. This improvement can be observed in movement of temperature peaks of both TGA and DSC curves to higher temperature values (about $20^{\circ} \mathrm{C}$ ).

\section{CONCLUSION}

The results showed that the shape and morphology of the copper powder, and filler at all, play a significant role in the phenomenon of electrical conductivity of the prepared samples and the appearance percolation threshold. The particles with highly developed free surface like dendrites having highly branched structure, such as galvanostatically obtained copper powder particles can easier form interparticle contacts at lower filler volume fractions than particles with more regular surface. Conductivity measurements have shown typical $S$ shape dependence, with the percolation transition from non-conductive to conductive region. The results showed that thermal stability of PMMA composites is improved comparing to pure polymers due to presence of conductive copper powder filler. Morphology of the samples showed presence of conductive pathways throughout the sample. Besides the filler morphology, polymer matrix type, as well as preparation method influenced the appearance of percolation threshold, which for the PMMA-Cu composites was at $2.89 \%$ (v/v), which is about three times lower than the percolation threshold obtained for the same type of composite with more rounded $\mathrm{Cu}$ particles used as filler.

\section{ACKNOWLEDGEMENT}

This work was financially supported by Ministry of Education, Science and Technological Development of the Republic of Serbia under the research projects: ON172037 and ON172046.

\section{References}

1. $\quad$ V.H. Poblete, M.P. Alvarez, V.M. Fuenzalida, Polym. Compos., 30 (2009) 328.

2. S.K. Bhattacharya, Metal Filled Polymers: Properties and Applications, Marcel Dekker: New York, 1986.

3. $\quad$ L. Xiangcheng, D.D.L. Chung, Compos. B: Eng., 30 (1999) 227.

4. Y. Xu, D.D.L. Chung, C. Mroz, Compos. A: Appl. Sci. Manuf., 32 (2001) 1749.

5. $\quad$ E.E. Tanrıverdi, A.T. Uzumcu, H. Kavas, A. Demir, A. Baykal, Nano-Micro Lett., 3 (2011) 99.

6. $\quad$ M. Thakur, Macromol., 21 (1988) 661.

7. $\quad$ H.S. Son, H.J. Lee, Y.J. Park, J.H. Kim, Polym. Int., 46 (1998) 308.

8. J. Bouchet, C. Carrot, J. Guillet, Polym. Eng. Sci., 40 (2000) 36.

9. L. Flandin, A. Chang, S. Nazarenko, A. Hiltner, E. Baer, J. Appl. Polym. Sci., 76 (2000) 894.

10. $\quad$ S. Kamel, Express Polym. Lett., 1 (2007) 546.

11. M.R. Al-bahrani, W. Ahmad, H.F. Mehnane, Y. Chen, Z. Cheng, Y. Gao, Nano-Micro Lett., 7 (2015) 298.

12. $\quad$ E. Alsharaeh, Mater., 9 (2016) 458.

13. F. Brouers, J. Phys. C: Solid State Phys. , 19 (1986) 7183. 
14. M.-L. Sham, J.-K. Kim, Compos. A: Appl. Sci. Manuf., 35 (2004) 537.

15. I. Ahmad, J. McCarthy, A. Baranov, Y. Gunko, Mater., 8 (2015) 5284.

16. S.-H. Jang, S. Kawashima, H. Yin, Mater., 9 (2016) 220.

17. C.-C. Chen, W.-F. Liang, Y.-H. Nien, H.-K. Liu, R.-B. Yang, Mater. Res. Bull., 96(2) (2017) 81

18. J. Delmonte, Metal/Polymer Composites, Van Nostrand Reinhold: New York, 1990.

19. X. Yang, K. Xu, R. Zou, J. Hu, Nano-Micro Lett., 8 (2016) 143.

20. Y. Yang, K. Shen, Y. Liu, Y. Tan, X. Zhao, J. Wu, X. Niu, F. Ran, Nano-Micro Lett., 9 (2016) 6.

21. M.Z. Iqbal, Rafiuddin, Mater. Res. Bull., 73 (2016) 296.

22. Y. Fu, L. Sun, C. Tian, H. Lin, Mater. Res. Bull., 48 (2013) 4491.

23. P.P. Parlevliet, H.E.N. Bersee, A. Beukers, Compos. A: Appl. Sci. Manuf., 38 (2007) 651.

24. B. Weidenfeller, M. Höfer, F.R. Schilling, Compos. A: Appl. Sci. Manuf., 35 (2004) 423.

25. G. Boiteux, J. Fournier, D. Issotier, G. Scytre, G. Marichy, Synth. Met., 102 (1999) 1234.

26. J. Tong, Y. Ma, R.D. Arnell, L. Ren, Compos. A: Appl. Sci. Manuf., 37 (2006) 38.

27. Y. Niu, Polym. Compos., 27 (2006) 627.

28. C.-H. Chen, C.-F. Mao, S.-F. Su, Y.-Y. Fahn, J. Appl. Polym. Sci., 103 (2007) 3415.

29. D.S. McLachlan., M. Blaszkiewicz, R.E. Newnham, J. Am. Ceram. Soc., 73 (1990) 2187.

30. D. Stauffer, A. Aharony, Introduction To Percolation Theory, 2nd ed., Taylor and Francis: London, 1992.

31. Y. Zweifel, C.J.G. Plummer, H.-H. Kausch, J. Mater. Sci., 33 (1998).

32. M.A. Valente, L.C. Costa, S.K. Mendiratta, F. Henry, L. Ramanitra, Solid State Commun., 112 (1999) 67.

33. S.M. Zhang, L. Lin, H. Deng, X. Gao, E. Bilotti, T. Peijs, Q. Zhang, Q. Fu, Express Polym. Lett., 6 (2012) 159.

34. M.M. Pavlović. Sinteza i karakterizacija elektroprovodnih kompozitnih materijala na bazi biorazgradivih polimera i prahova metala, Ph.D. Thesis, University of Belgrade, Faculty of Technology and Mettalurgy, Belgrade, 2015.

35. M.M. Pavlović, V. Ćosović, M.G. Pavlović, N. Talijan, V. Bojanić, Int. J. Electrochem. Sci., 6 (2011) 3812.

36. M.M. Pavlović, V. Ćosović, M.G. Pavlović, V. Bojanić, N.D. Nikolić, R. Aleksić, Int. J. Electrochem. Sci., 7 (2012) 8883.

37. M.M. Pavlović, M.G. Pavlović, V. Panić, N. Talijan, L. Vasiljević, M.V. Tomić, Int. J. Electrochem. Sci., 7 (2012) 8894.

38. M.M. Pavlović, M.G. Pavlović, V. Ćosović, V. Bojanić, N.D. Nikolić, R. Aleksić, Int. J. Electrochem. Sci., 9 (2014) 8355.

39. R.T.d. Hoff, F.N. Rhines, Quantitative microscopy, McGraw-Hill: New York, 1968.

(C) 2018 The Authors. Published by ESG (www.electrochemsci.org). This article is an open access article distributed under the terms and conditions of the Creative Commons Attribution license (http://creativecommons.org/licenses/by/4.0/). 